\title{
Sustainable Catalytic Processes Driven by Graphene-Based Materials
}

\author{
Sergio Navalón ${ }^{1, *}$, Wee-Jun Ong ${ }^{2}$ and Xiaoguang Duan ${ }^{3, *} \mathbb{D}$ \\ 1 Departamento de Química, Universitat Politècnica de València, C/Camino de Vera, s/n, 46022 Valencia, Spain \\ 2 School of Energy and Chemical Engineering, Xiamen University Malaysia, Selangor Darul Ehsan, \\ Sepan 43900, Malaysia; weejun.ong@xmu.edu.my \\ 3 School of Chemical Engineering and Advanced Materials, The University of Adelaide, \\ Adelaide, SA 5005, Australia \\ * Correspondence: sernaol@doctor.upv.es (S.N.); xiaoguang.duan@adelaide.edu.au (X.D.)
}

Received: 27 May 2020; Accepted: 3 June 2020; Published: 5 June 2020

check for updates

\begin{abstract}
In the recent two decades, graphene-based materials have achieved great successes in catalytic processes towards sustainable production of chemicals, fuels and protection of the environment. In graphene, the carbon atoms are packed into a well-defined $\mathrm{sp}^{2}$-hybridized honeycomb lattice, and can be further constructed into other dimensional allotropes such as fullerene, carbon nanotubes, and aerogels. Graphene-based materials possess appealing optical, thermal, and electronic properties, and the graphitic structure is resistant to extreme conditions. Therefore, the green nature and robust framework make the graphene-based materials highly favourable for chemical reactions. More importantly, the open structure of graphene affords a platform to host a diversity of functional groups, dopants, and structural defects, which have been demonstrated to play crucial roles in catalytic processes. In this perspective, we introduced the potential active sites of graphene in green catalysis and showcased the marriage of metal-free carbon materials in chemical synthesis, catalytic oxidation, and environmental remediation. Future research directions are also highlighted in mechanistic investigation and applications of graphene-based materials in other promising catalytic systems.
\end{abstract}

Keywords: graphene; green chemistry; carbocatalysis; active sites; advanced oxidation; organic synthesis; hydrogenation

\section{Introduction}

The discovery and exploitation of catalysts in the last century has significantly renovated the chemical industry and boosted the rapid development of human society in all the aspects of food, energy, and environment. Most chemical processes are driven by acids/bases and zeolites, as well as metals and metal oxides. Noble metals such as $\mathrm{Pt}, \mathrm{Pd}, \mathrm{Au}$ or Ru possess high activities in electrocatalysis [1], CO oxidation [2], petroleum refining [3], and organic synthesis [4], whereas the industrialization is limited by scare resources, high cost, and low stability in a long-term operation. Transition metal oxides (TMO) possess multivalent sites and are widely used in hydrogenation/dehydrogenation reactions and fuel cells [5-7]. However, due to the complicated composition, termination, size, and morphology, the rational optimization of well-defined metal oxides towards oriented heterogeneous reaction and unveiling the regime in catalytic processes are challenging [8]. TMO catalysts also suffer from poor stability in acidic or basic solutions and may potentially induce secondary contamination during use and disposal. To this end, carbonaceous materials are promising alternatives which are of elemental abundance, environmental friendliness, and structural robustness. 
The term of "carbocatalysis" refers to heterogeneous catalysts that are composed of carbon as the major element and the active compounds [9]. Among the diverse carbon allotropes, graphene and graphene-based materials have attracted high interest from the scientific community. Graphene is constructed with one atomic layer of $\mathrm{sp}^{2}$-hybridized carbons compacted in a honeycomb lattice, with a theoretical surface area of $2600 \mathrm{~m}^{2} / \mathrm{g}$, thermal conductivity of $\sim 5000 \mathrm{~W} \mathrm{~m}^{-1} \mathrm{~K}^{-1}$ and a very high electrical conductivity $[10,11]$. With defects and curvature, graphene can be rolled into fullerene and carbon nanotubes, or stacked into multi-layered graphite (Figure 1). More intriguingly, the artificially derived graphene is normally imperfect, bearing a variety of oxygen-containing groups, dangling bonds, and structural defects in plane and at the boundaries. Different from the highly conjugated graphitic lattice, these imperfect sites induced abnormal electronic and chemical features to the graphene, and are identified as the intrinsic active sites in carbon-based catalysis [12,13]. In particular, since Hummers and co-workers reported the approach to synthesize graphene oxide (GO) from natural graphite flakes in 1958, tremendous efforts have been dedicated to improve the approach for the lab-scale production of GO for further synthesis and functionalization of graphene (namely reduced graphene oxide, rGO) [14-16]. The open structure of two dimensional GO allows for both structural and compositional flexibility, further engineering pristine graphene with heteroatom dopants, oxygen functionalities, and coupling with other materials [17]. Both surface modification and structural engineering can bring new features to graphene in catalysis. Moreover, since the graphene-based materials possess open, well-defined and simple structures, offering tremendous opportunities for functionalization, the characterization and determination of the structure/functionalities-catalysis relations in chemical reactions.

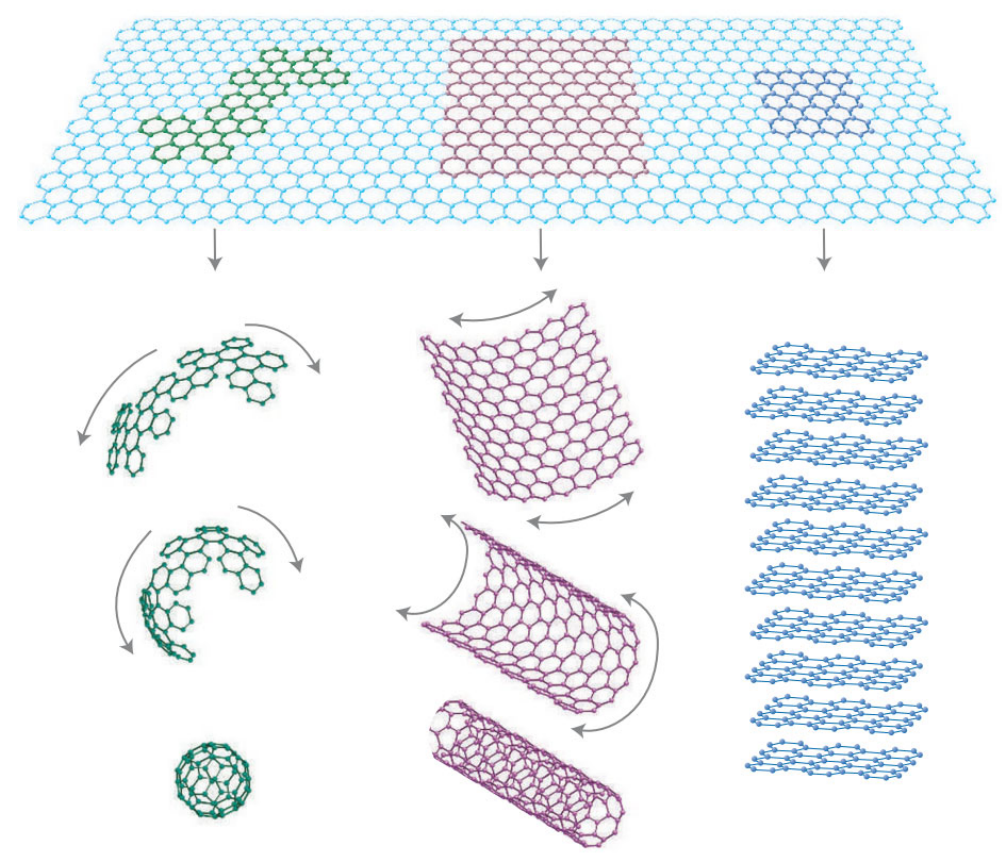

Figure 1. Transformation of two-dimensional graphene into other allotropes such as fullerene, carbon nanotubes, and stacked graphite flakes. Reprinted with permission from reference [18].

Here, the guest editors of the Special Issue would like to highlight of the recent achievements of graphene-based materials in green catalytic processes. We will first introduce the diverse potential catalytic centers in graphene-based materials, the synthesis and features in carbocatalysis. Then, we choose several characteristic systems to showcase the state-of-the-art of carbocatalysis in hydrocarbon conversions and environmental purification, covering advanced oxidation processes (AOPs), organic synthesis, selective oxidation, hydrogenation reactions. Finally, we provide some directions to the rational design and synthesis, advanced characterizations and mechanistic studies of graphene-based materials in heterogeneous catalysis. 


\section{Active Sites in Graphene}

Artificially derived graphene has a typically non-perfect $\mathrm{sp}^{2}$-conjugated carbon lattice. A diversity of structural defects, functional groups, dopants and impurities are simultaneously generated, which are of high chemical potential to coordinate redox processes in chemical reactions. This section will briefly introduce the typical catalytic centers in graphene, their production, features and functions.

Basal plane the $\mathrm{sp}^{2}$ carbons in the basal plane of graphene share a highly conjugated and delocalized $\pi$ system, which is believed to be chemically inert. The graphitic carbon lattice is of high conductivity and aromatic degree, which can facilitate the electron-transfer process in redox reactions and adsorption/activation of organic molecules via $\pi-\pi$ interactions and electrostatic interactions $[19,20]$. In particular, graphene allotropes such as carbon nanotubes and fullerene possess a bent carbon network. The curved carbon structure leads to the uneven distribution of electrons at the concave and convex sides and enables the excitation of partial s electrons into the p orbitals [21]. The carbon atoms are supposed to process redistributed electronic structures and semi-metal properties, distinguishing them from planar carbons in catalysis.

Oxygen functionalities Graphene-based materials are inherently functionalized with oxygen groups from the manufacture processes to saturate the metastable defects, dangling bonds, and boundaries. Concentrated acids $\left(\mathrm{H}_{2} \mathrm{SO}_{4}, \mathrm{HNO}_{3}, \mathrm{H}_{3} \mathrm{PO}_{4}\right)$ and mild oxidants $\left(\mathrm{H}_{2} \mathrm{O}_{2}, \mathrm{O}_{2}, \mathrm{CO}_{2}\right)$ are also used to potentially decorate carbon materials with oxygen-containing groups. The categories of oxygen groups are diverse and mostly located on the periphery of graphene [19]. Based on their capacities to donate or accept protons, the oxygen functionalities are grouped into acidic, neutral and basic species. So far, a large volume of studies have been conducted on the activities and intrinsic catalytic centers of the oxygen groups in different studies [22,23]. Both the quantity and species of the oxygen groups may affect the reactivity of graphene in carbocatalysis.

Heteroatom doping One of most fascinating techniques in graphene functionalization is chemical doping, which brings in new active sites, regulates the electron/spin cultures of carbon lattice, and remarkably speeds up the carbocatalytic reactions [24,25]. Metal-free elements such as boron, nitrogen, phosphorus, sulfur, and halogens are extensively used as the dopants, which can be introduced by the post-treatment of $\mathrm{GO}$ with the organic/inorganic precursors that contain the elements [26,27]. Some bottom-up strategies are also developed to directly synthesize chemically modified graphene via a one-step approach [28-30]. The substitution with alien atoms effectively changes the charge density of the surrounding carbons and alters their catalytic behaviors in a redox process. The direction of electron transfers between the dopants and the host (carbons) is determined by their different electronegativities, as well as the density of state (DOS) of the highest/lowest occupied molecular orbitals (HOMO/LOMO) compared to the Fermi level of carbons in intact graphene [31,32]. Additionally, the doping level is determined by the relative radius of the alien atom to carbon as well as the electronic configuration to form covalent bond with $\mathrm{sp}^{2}$ carbon. Notably, the doping amount should be kept at a rational level within a limit, otherwise the structural integrity of graphene cannot be maintained. More recently, the metal-free dopants, especially pyridinic nitrogen, have been used as anchoring sites to coordinate with isolated transition/noble metal atoms in the graphene layer, offering a new class of single-atom carbocatalysts in chemical reactions [33-35].

Defects During the synthesis and functionalization, a certain amount of extrinsic or intrinsic defects will be inevitably induced into the graphene lattice. These structural defects include zigzag/armchair edges, vacancies, dangling bonds, and topological defects (Figure 2) [8]. The point defects, such as vacancies in the basal plane and zigzag/armchair edges at the lattice boundary, break the symmetry and homogeneity of the conjugated $\mathrm{sp}^{2}$ systems. The localized electrons in edging sites afford the boundary carbon atoms with unpaired $\pi$ electrons, localized spins and close DOS to Fermi level, demonstrating high chemical potential in catalytic processes [36,37]. Additionally, the topological defects are the non-hexagonal rings of the pentagon, heptagon, octagon, and their combinations. These defects can induce local lattice distortion (Gaussian curvature), shorten/prolonged bond distance, and re-optimize electron orbitals, possessing intriguing electronic structures in catalysis $[38,39]$. Due to 
high activity, these defects have been artificially induced in graphene-based materials in recent studies by hierarchical pore engineering [40], acid etching [41], plasma treatment [42], or selective removal of heteroatoms by thermal annealing [43].

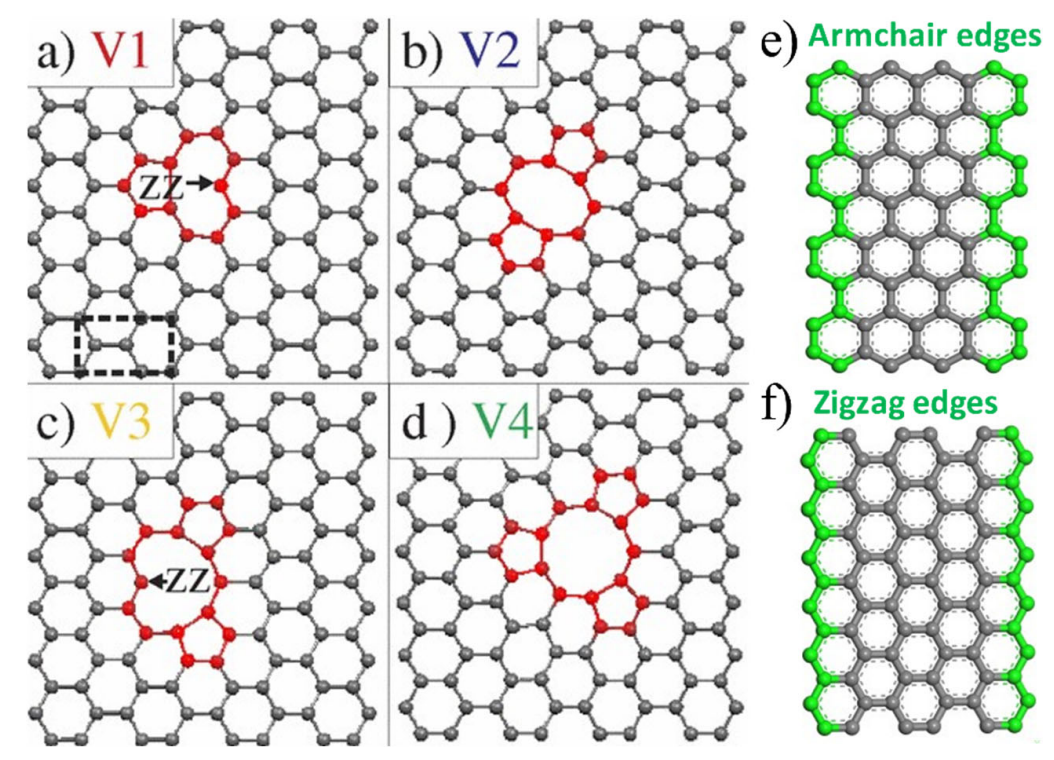

Figure 2. Scheme of (a-d) different topological defects (Reprinted with permission from reference [44]); (e) armchair edges, and (f) zigzag edges in graphene.

\section{Advanced Oxidation Processes}

Modern industrialization and rapid urbanization have produced large volumes of hazardous and persistent organic contaminants into aquatic systems. The conventional wastewater treatment plants rely on physical separation and aerobic/anaerobic bio-digestion, which cannot completely remove all the toxic micropollutants in water. To this end, advanced oxidation processes (AOPs) are developed to use diverse peroxides such as hydrogen peroxide $\left(\mathrm{H}_{2} \mathrm{O}_{2}\right)$, ozone $\left(\mathrm{O}_{3}\right)$, peroxymonosulfate (PMS), and peroxydisulfate (PDS) to produced highly reactive oxygen species (ROS) to decompose the contaminants. The typical ROS include sulfate radicals $\left(\mathrm{SO}_{4}^{\bullet-} 2.5-3.1 \mathrm{~V}\right)$, hydroxyl radicals $\left({ }^{\bullet} \mathrm{OH}, 1.8-2.7 \mathrm{~V}\right)$, superoxide ion radicals $\left(\mathrm{O}_{2}{ }^{\bullet-}, 1.70 \mathrm{~V}\right)$, and singlet oxygen $\left({ }^{1} \mathrm{O}_{2}, 2.2 \mathrm{~V}\right)$, etc. Most ROS have a higher oxidation capacity than the parent peroxides and can directly decompose and mineralize the organic pollutants into harmless products. Different from physical stimulations such as ultrasonic [45], ultra-violet radiation [46], heat [47,48] and electricity [49], diverse transition and noble metals [50] with redox sites and optimal d orbitals can catalyze the decomposition of superoxides to produce ROS without an intensive energy input. However, metal catalysts suffer from the inherent demerits of high cost, toxicity and poor stability. In this regard, graphene-based materials stand out as green and robust alternatives to drive the AOPs system [51-53].

Wang's group first applied rGO as a metal-free catalyst to activate PMS to generate sulfate radicals for phenol oxidation in aqueous solution, outperforming the benchmark transition metal catalysts $\left(\mathrm{Co}_{3} \mathrm{O}_{4}\right.$ and $\left.\mathrm{MnO}_{2}\right)$ [54]. Via rational material design and theoretical computations, the basic carbonyl groups and zigzag/armchair edges at the lattice boundary are the primary active sites [55-57]. The electron-rich ketonic groups can either experience a redox cycle to produce sulfate radicals or combine with PMS to form an epoxy adduct to mediate singlet oxygen (Figure 3) [58,59]. Incorporating nitrogen dopants into graphene can remarkably boost the catalytic activity for PMS activation and catalytic oxidation [60-63]. Among the nitrogen dopants, graphitic nitrogen has been demonstrated as the most reactive nitrogen species, which leads to positively-charged carbon atoms in the local domain [64]. These carbon atoms are the intrinsic active sites to strongly bond with the oxygen atoms in PMS molecule to coordinate a nonradical oxidation pathway [65]. Moreover, nitrogen dopants 
at the structural defects (vacancies and edges) show a synergistic effect for improved carbocatalysis in AOPs [66-68]. Co-doping sulfur with nitrogen in graphene at a rational level further improves the activity of graphene for PMS activation, due to the optimized electronic configuration and enlarged catalytic areas (Figure 4) $[69,70]$. Introducing boron into the $\mathrm{N}$-doped graphene results in more reactive carbons and improves the performance of $\mathrm{N}$-doped graphene, and the catalysis is determined by the relative distance/position of $\mathrm{N}$ and $\mathrm{B}$ atoms [71,72]. More recently, nanodiamonds (NDs) have been graphitized at high temperatures into $\mathrm{sp}^{2} / \mathrm{sp}^{3}$ hybrids with graphitic shells and a diamond core $[73,74]$. The reactivity of the annealed NDs in AOPs is dependent on the relative proportion of $\mathrm{sp}^{2}$ and $\mathrm{sp}^{3}$ carbons as well as the surface chemistry (dopants and functionalities) of the outermost graphene sphere [75-78]. Additionally, embedded transition metal nanoparticles, such as Co [79,80], Fe [81,82], Mn [83], and Ni [84,85], beneath graphene not only afford the carbocatalyst with a magnetic property, but also increase the charge density of surface carbons via interfacial coupling. The synergy of metal-graphene hybrids boosts the electron transfer to PMS for evolution of ROS and intensifies the stability of carbon in oxidative environment [86].

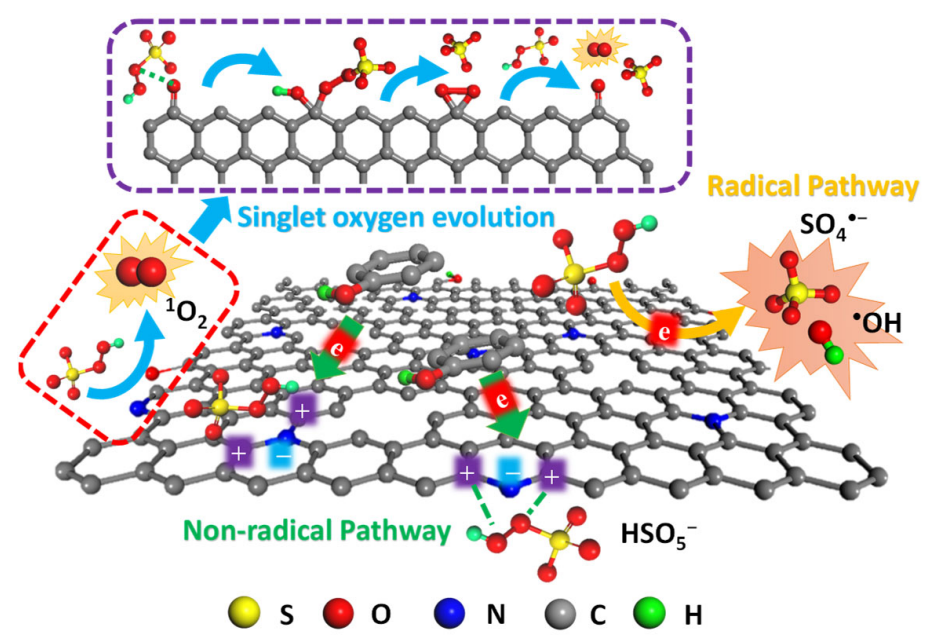

Figure 3. Illustration of different reaction pathways: singlet oxygenation, nonradical electron transfer, and radical pathways. Reprinted with permission from reference [59]

Similarly, graphene-based materials are also capable of activating PDS for catalytic oxidation, whereas most of the systems are based on nonradical reactions. For instance, singlet oxygen was discovered in the PDS/rGO systems, generated at the ketonic groups and edging defects $[87,88]$. Over the intact graphitic carbon network, the electron-transfer regime typically dominates the oxidation, where PDS is activated and confined on the highly-conjugated basal plane of carbocatalysts as a metastable intermediate [89,90]. The intermediate elevates the redox potential of the carbon surface and directly oxidize the organics via electron abstraction. By rationally regulating the surface functionalities of the carbocatalyst, the adsorption quantity of PDS can be precisely tailored [91]. Therefore, the redox potential of a carbocatalytic system is controlled to be able to selectively remove target organic pollutants based on its electron-donating properties [92,93]. Interestingly, N-doping cannot significantly improve the reactivity of graphene-based materials for PDS activation, which is different from the PMS-based systems [94]. This is partially because of the large and symmetrical molecular structure of PDS and limited improvement in adsorption in the N-doped areas [95,96]. The construction of graphene nanosheets into porous structures or three-dimensional frameworks not only boost the kinetics of reactant diffusion, but also dramatically improves the adsorption capacity of persulfates to break the limit [97-99]. 


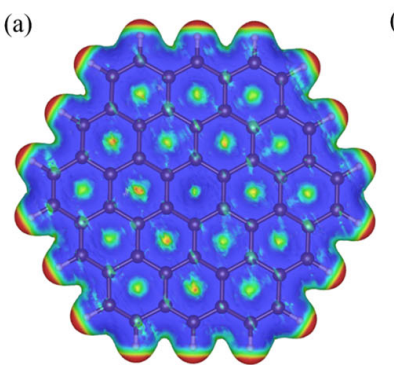

(d)

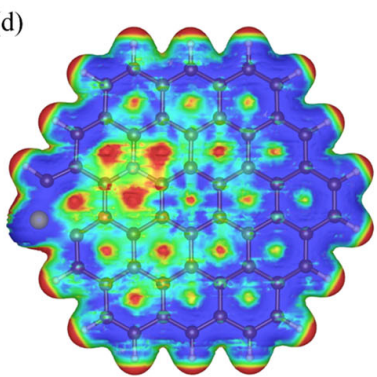

(b)

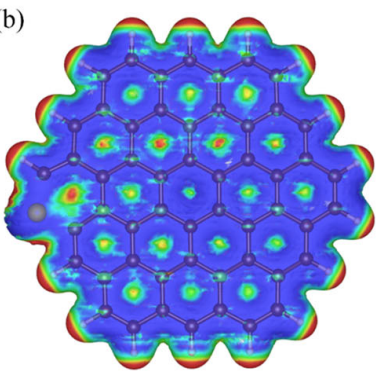

(c)

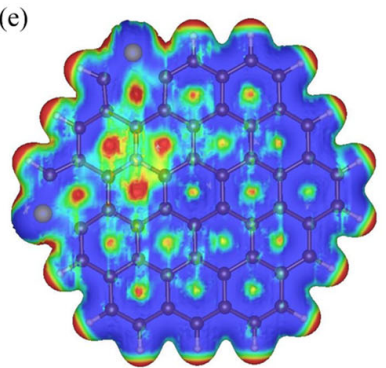

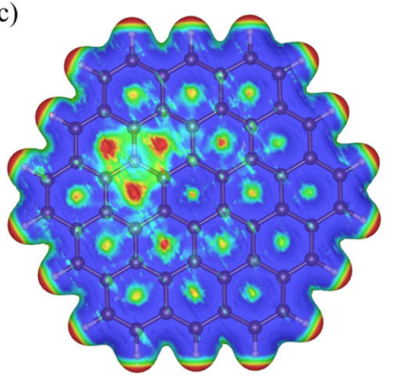

Figure 4. Electrostatic mappings of (a) pristine graphene, (b) S-doped, (c) N-doped (graphitic nitrogen), (d), S-, N-codoped, and (e) S-, S-, N-doped graphene models. Reprinted with permission from reference [70].

\section{Chemical Synthesis and Green Catalysis}

The development of the chemical industry has been possible, in a large extent, due to the design of active, selective and stable catalysts [100,101]. Traditionally, most of the catalysts applied in the industry are based on transition metal elements with the general role of acting as Lewis or redox sites. Nowadays, more than $80 \%$ of chemical industrial processes use a catalyst. The global catalyst market is dominated by heterogeneous catalysis [102]. The main advantage of heterogeneous catalysis is the easy separation of catalyst from the reaction mixture that allows the development of economical and simplified continuous flow processes and recovery and reuse of the solid catalysts.

For the sake of sustainability, it would be convenient to develop heterogeneous processes based on cost-effective metal-free catalysts [103-112]. Carbon is an earth-abundant element and can be fabricated into diverse structures with versatile functionalities, standing out as the promising candidate for green catalysis with high efficiency and selectivity [113-117]. The area of catalysis dealing with metal-free carbon catalysts is called "carbocatalysis". In the 1980's, some pioneering studies appeared in this area [118-121]. One of these examples reported the oxidative dehydrogenation reaction of ethylbenzene to styrene using a crystalline zirconium phosphate as a catalyst (Figure 5) [120]. Styrene is one of the important commodities of the petrochemical industry especially for the production of plastics and resins. This study showed that a black carbonaceous material generated during the course of the reaction was the real active phase in catalysis [120]. Furthermore, it was demonstrated that the presence of molecular $\mathrm{O}_{2}$ was required during the course reaction at high temperature for the formation of the active centers that were attributed to hydroquinone/quinone or phenol/aroxyl-like moieties in the active coke.

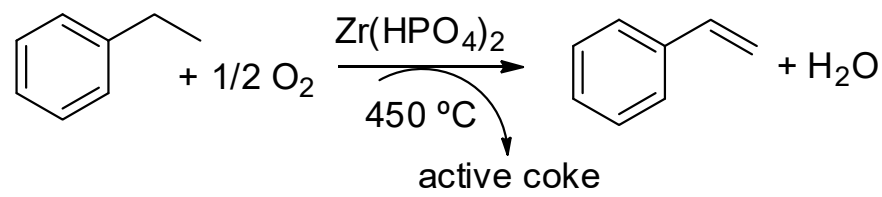

Figure 5. Catalytic oxidative dehydrogenation of ethylbenzene to styrene and formation of active coke. 
Since then, the number of examples using different carbonaceous materials or carbon allotropes as metal-free carbon materials have continuously grown [105-122]. Moreover, the discovery of graphene and related materials since 2004 have expanded the field of carbocatalysis in a large extent $[18,23,106]$. Nowadays, GO [123,124] and rGO [125] have become the most popular graphene-based carbocatalysts. Some of the main reasons of the wide use of GO and rGO as metal-free catalysts include their availability in sufficient quantities due to easy preparation as well as their tunability for functional groups to act as active sites in specific reactions. Currently, graphene-based materials have been reported as metal-free catalysts for several reactions including oxidation, reduction, coupling, and acid-base reactions. The reader is referred to some existing reviews covering the use of graphene as metal-free catalysts for these types of reactions [22,23,103,104,106].

In the present perspective, while paying credit to prior pioneering work, the main focus will be allocated to the recent examples of graphene-based carbocatalysts for two of the most important reactions for the chemical industry, namely oxidations and hydrogenations using molecular $\mathrm{O}_{2}$ and $\mathrm{H}_{2}$, respectively.

\section{Oxidation Reactions}

One of the most important processes in the chemical industry is the oxidation of organic compounds [126-129]. Commonly, these oxidation reactions are performed using transition metal catalysts as redox centers combined with oxidants such as hydrogen peroxide, organic peroxides or hydroperoxides. Currently, one of the challenges in the area of catalytic oxidation is the development of active, sustainable and cost-efficient catalysts to perform selective oxidation reactions using molecular oxygen as an oxidant [22].

In this context, Bielaswky and co-workers reported, in 2010, a pioneering work on the use of GO as a carbocatalyst to promote the aerobic oxidation of benzyl alcohol to benzaldehyde (Figure 6) [123]. The catalyst was prepared by graphite oxidation following Hummer's method and further ultrasound exfoliation. Reuse experiments showed that GO maintains its activity when using catalysts loadings higher than $50 \mathrm{wt} \%$. However, the use of GO loadings lower than $20 \mathrm{wt} \%$ results in a benzyl alcohol conversion lower than 5\%. Characterization data of the used GO show that the deactivation of the catalyst is related with partial reduction of GO to rGO. Importantly, experimental and theoretical studies proposed epoxy groups on GO as the active sites for the observed catalytic activity [130]. In spite of the low TON achieved $\left(1.1 \times 10^{-2}\right)$ by GO as the catalyst for benzyl alcohol oxidation, this work is considered one of the milestones in the field of carbocatalysis, sparking the development of the field.

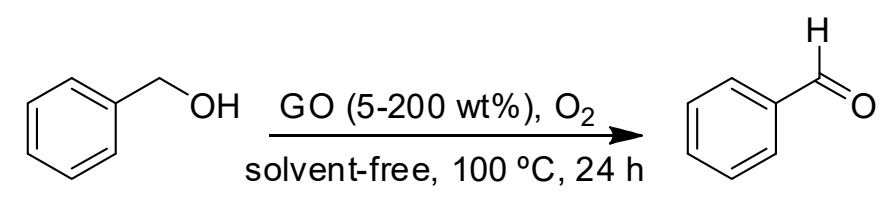

Figure 6. Aerobic oxidation of benzyl alcohol using graphene oxide-based catalysts.

Since then, the number of studies showing the potential application of graphene-based materials as catalysts for oxidation reactions have continuously grown $[9,22]$. Among them, particularly relevant-for the sake of sustainability-are those papers that have shown the potential use of graphene as active catalysts for molecular $\mathrm{O}_{2}$ activation. In this line, Loh and co-workers reported that the activity for benzyl amine oxidative coupling of GO obtained by Hummer's method can be increased by simple basic and acids treatments (Figure 7) [36]. It was proposed that these washings removed the amorphous acid carbon debris deposited on GO blocking holes that become released upon these washings increasing the number of defects on the washed GO. The obtained GO can be used for six consecutive catalytic cycles of oxidative benzyl amine coupling with a negligible loss in activity and maintaining a product yield higher than $95 \%$. Importantly, the presence of carboxylic acid groups 
close to unpaired electrons at the edge were proposed as the active sites for $\mathrm{O}_{2}$ activation to superoxide radicals as the primary reactive oxygen species, promoting benzylamine oxidation to the corresponding imine. This work represents one of the first examples showing graphene-based materials as metal-free catalysts for aerobic oxidations under solvent-free conditions in a low catalyst-to-substrate mass ratio.

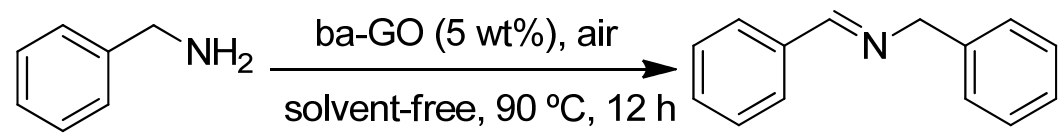

Figure 7. Aerobic oxidation of benzylamine using base then acid washed graphene-oxide (GO) as a catalyst.

Currently, a step forward in the development of graphene-based materials is the preparation of the catalyst materials with well-defined functional groups as the catalytic sites for specific reactions [22]. The reader is referred to some existing reviews summarizing the current knowledge on the nature of the active sites on graphene-based materials for several catalytic reactions [22]. In this line, recently, we have reported the influence of the GO reduction method on its catalytic activity for molecular $\mathrm{O}_{2}$ activation leading to the selective oxidative coupling of benzylamine to its corresponding imine [131]. Figure 8 illustrates some of the proposed structural differences in rGO samples depending on the chemical or thermal reduction processes.

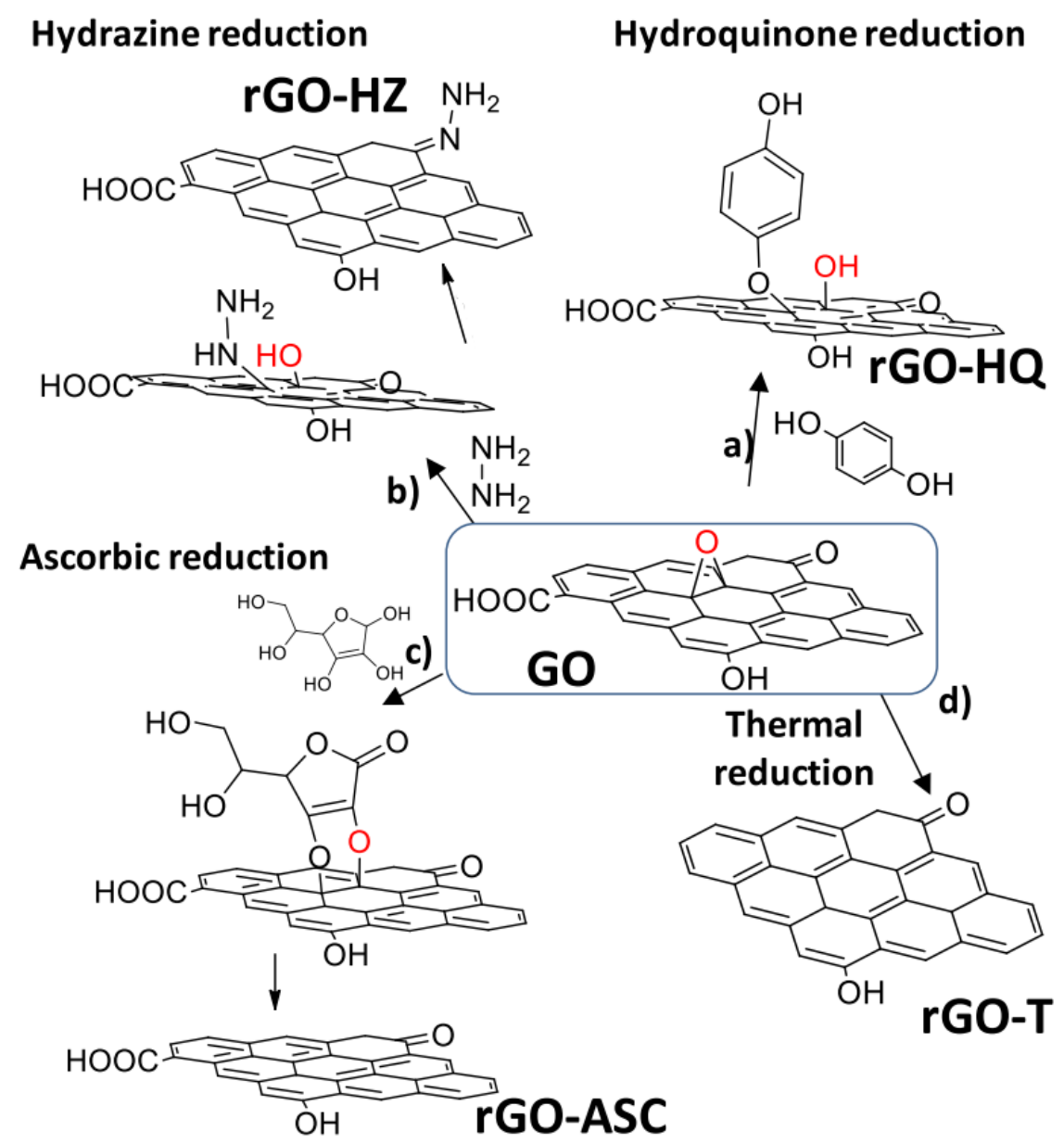

Figure 8. Variation of the nature of functional groups in reduced graphene-oxide (rGO) depending on the reduction treatment: (a) hydroquinone, (b) hydrazine, (c) ascorbic acid as reducing agents, or (d) by thermal reduction. Reprinted with permission from reference [131]. 
A series of rGO samples were prepared from a common GO precursor and then, under different reduction treatments, were tested for the aerobic oxidation of benzylamine [131]. The rGO sample prepared with hydroquinone as a GO reducing agent exhibited the highest catalytic activity (Figure 9a). Interestingly, the catalytic activity depends on the degree of rGO functionalization with hydroquinone/quinone-like moieties. Thus, the higher the amount of hydroquinone employed, the higher catalytic activity observed, due to the higher hydroquinone/quinone-like moieties covalently anchored to the rGO. Importantly, it was demonstrated that the catalytic process is truly heterogeneous (Figure 9a) and the catalyst could be reused several times with only a slight decrease in the catalytic activity (Figure 9b). Control experiments using Mn(II) acetate as catalyst were performed to rule out that the presence of trace amounts of manganese in the carbocatalyst acts as active sites of the reaction (Figure 9b).

a)
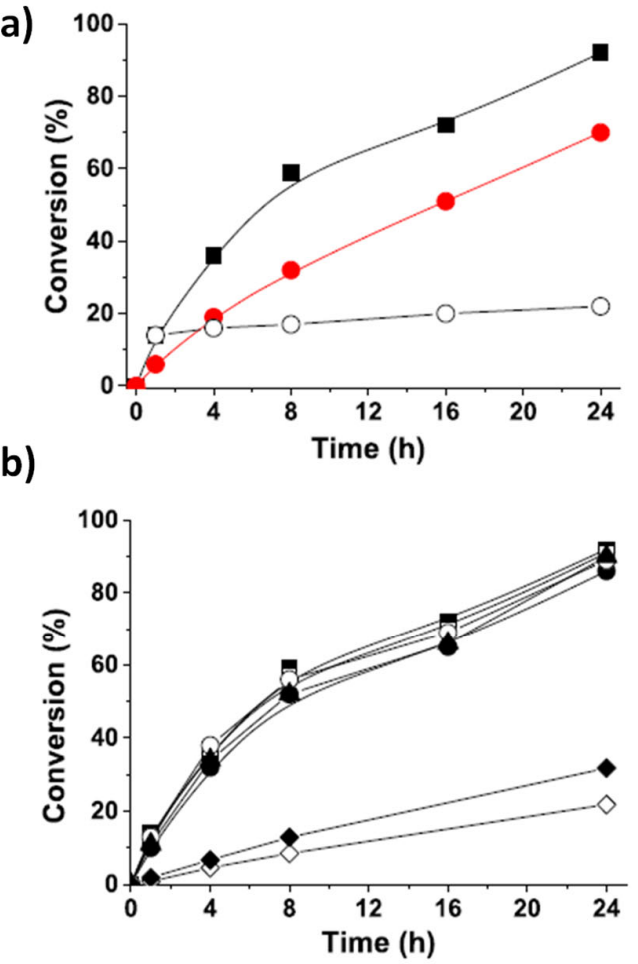

c)

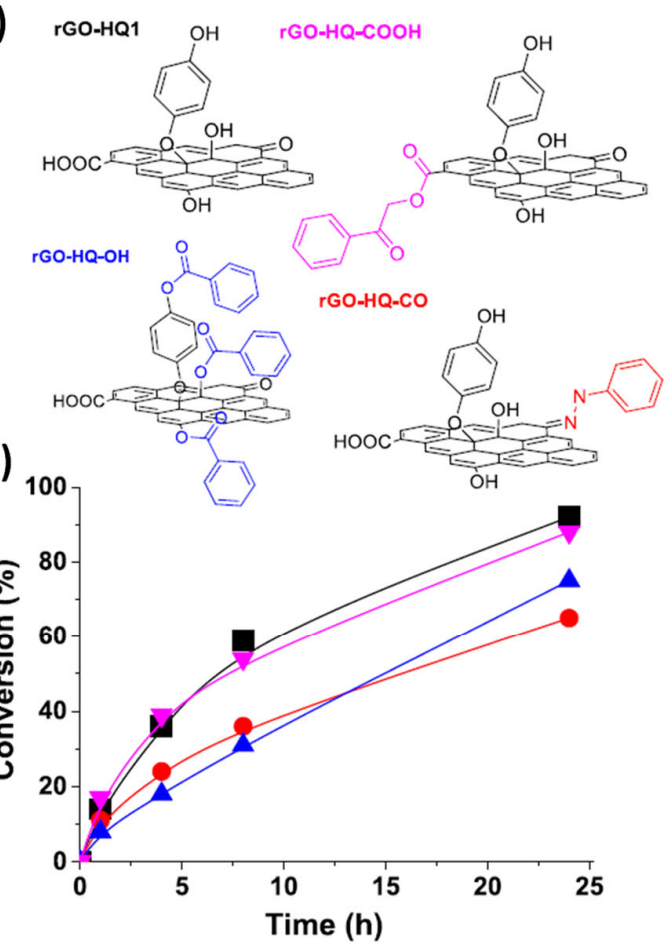

Figure 9. (a) Time conversion-plot for the aerobic oxidation of benzylamine using rGO-HQ1 (a), rGO-HQ2 $(\bullet$, red) and after hot filtration test using rGO-HQ1 (O); (b) reusability of rGO-HQ1 (first $\mathbf{\square}$, second $\square$, third $\bigcirc$, fourth $\boldsymbol{\Lambda}$, fifth $\bullet$ ) and catalytic activity of manganese(II) acetate (0.6 $\diamond$ or $2 \triangleleft \mathrm{mg}$ of Mn(II) equivalent to 30 or $100 \mathrm{ppm}$ of $\mathrm{Mn}(\mathrm{II})$ in the solid catalyst). (c) Selective masking of oxygen-functional groups present in the rGO-HQ1 sample including carboxylic groups (rGO-HQCOOH), carbonyls (rGO-HQ-CO) or alcohols (rGO-HQ-OH). (d) Time-conversion plots for the aerobic oxidation of benzylamine using rGO-HQ1 (घ), rGO-HQ-COOH ( $\boldsymbol{\nabla}$, pink), rGO-HQ-CO $(\bullet$, red) or rGO-HQ-OH $(\mathbf{\Lambda}$, blue) as carbocatalysts. Reaction conditions: benzylamine $(1 \mathrm{~mL})$, catalyst $(20 \mathrm{mg})$, oxygen purged, $80^{\circ} \mathrm{C}$. Reprinted with permission from reference [131].

Furthermore, selective masking experiments of the presumed functional groups presented in the rGO-HQ sample are in favor of hydroquinone/quinone-like groups as the active sites responsible for the observed catalytic activity (Figure 9c,d). This work is one of the first reports showing the possibility to obtain rGO samples with an enhanced activity due to the appropriate selection of reducing agents to promote both the GO reduction and its functionalization with active sites for specific reactions. 


\section{Hydrogenation Reactions}

Hydrogenation reactions using $\mathrm{H}_{2}$ are also some of the most widely used processes in petrochemical and fine chemical industry as well as in organic synthesis [132,133]. Typically, hydrogenations are carried out using noble metal based catalysts such as $\mathrm{Pt}$, Pd or $\mathrm{Rh}$ as well as other base metals such as $\mathrm{Ni}$ as active centers. For example, the steam cracking of naphtha is one of the general processes for the production of ethylene in the chemical industry [134,135]. The process, however, also generates acetylene, which is highly detrimental and undergoes undesirable polymerization reactions. One of the possible ways to purify the effluent is selective hydrogenation of acetylene to ethylene. Other important hydrogenations in the preparation of bulk chemicals is the selective reduction of nitro groups to their corresponding amino derivatives [136,137].

The activation of molecular $\mathrm{H}_{2}$ to promote hydrogenation of organic compounds has become one of the challenges in carbocatalysis [22]. In one seminal work, Garcia and co-workers reported graphene-based materials to promote the selective hydrogenation of acetylene in the presence of large excess of ethylene (Figure 10a) [138]. Catalytic and spectroscopic data showed that the graphene obtained from the pyrolysis of alginate was the most active, selective and stable catalyst under the study. In contrast, doped-graphene with nitrogen, phosphor or sulfur catalysts favor the formation of dimers or oligomers. Moreover, the nitrogen- or phosphorous-doped graphene appears unstable under the reaction conditions, leading to the complete or partial removal of the doping heteroatoms in the graphene with time on stream.

a)

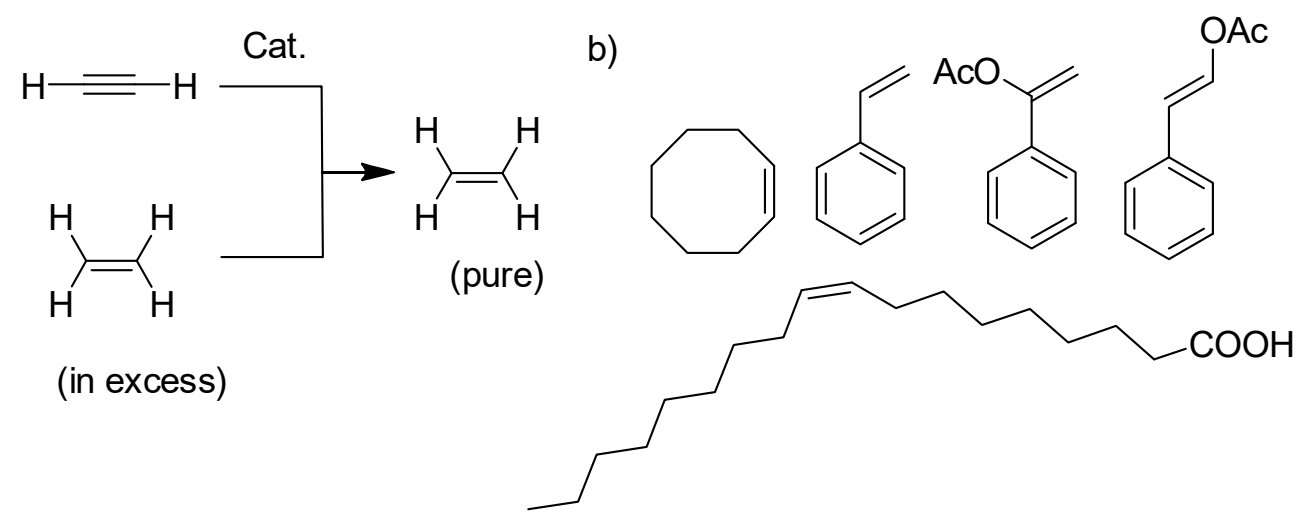

Figure 10. (a) Selective hydrogenation of acetylene in the presence of excess of ethylene in the presence of graphene as carbocatalysts; (b) chemical structures of alkenes employed for the liquid phase hydrogenation using graphene obtained from alginate.

Importantly, the alginate-derived graphene also performed actively in the liquid-phase selective hydrogenation of alkenes with good to excellent yields (Figure 10b). The frustrated Lewis acid-base pairs on the graphene sheets are the active sites responsible for $\mathrm{H}_{2}$ activation, as supported by temperature programmed desorption (TPD) experiments using $\mathrm{NH}_{3}$ or $\mathrm{CO}_{2}$ as probe molecules of acid or basic sites. This is in agreement with previous examples with frustrated Lewis acid-base units to activate molecular $\mathrm{H}_{2}$ through the polarization of the molecule into $\mathrm{H}^{+}$- or $\mathrm{H}^{-}$-like sites and later transferred to the organic molecules $[132,139,140]$. In a related study, Su and co-workers showed the possibility to prepare graphitized nanodiamonds with nitrogen and boron atoms in the carbon lattice acting as frustrated Lewis acid-base pairs to promote the hydrogenation of cyclooctene working at $220^{\circ} \mathrm{C}$ and 100 bar of $\mathrm{H}_{2}$ pressure [141].

In other studies, Garcia and co-workers have also shown the possibility to employ graphene-based materials to perform the hydrogenation of nitrocompounds, although there is still room to improve the selectivity in the presence of $C=C$ double bonds [142]. Very recently, nitrogen-doped graphene obtained from pyrolysis of chitosan has been employed for the Sabatier hydrogenation of $\mathrm{CO}_{2}$ to $\mathrm{CH}_{4}$ at $500{ }^{\circ} \mathrm{C}$ [143]. The superior activity and stability of $\mathrm{N}$-doped graphene respect to other graphene-based 
materials has been attributed to the pyridinic groups in the graphene sheets that favor the adsorption of $\mathrm{CO}_{2}$ and formation of carbamate-type adsorbents.

Overall, these works exemplify the possibility to develop metal-free hydrogenations while there is still room for improvement of their activity towards the use of low reaction temperatures and hydrogen pressures.

\section{Concluding Remarks}

Graphene-based materials have demonstrated great versatility and capacity in driving green chemical reactions, and are promising to replace the transition/noble metal catalysts in industrial catalytic processes with high reactivity, selectivity and stability. One challenge in the practical application of graphene is the high cost of manufacturing processes, which are highly energy/chemical intensive. To this end, advanced strategies are encouraged to be developed to produce scalable, low-cost and high-quality graphene-based materials. Facile approaches in the regeneration of the carbocatalysts and recovery of active sites are also important for economic effectiveness and long-term operations. More importantly, through post-treatment or bottom-up design, it is desirable to develop graphene with specific active sites for target reactions. In achieving this, a deep and comprehensive understanding of material chemistry, intrinsic catalytic centers, as well as reaction pathways, is the prerequisite. To this end, theoretical calculation is a handy tool to predict the properties and electronic structures of different potential active sites in graphene, and their behaviors in catalytic reactions. A pre-screen of the carbon configurations and functional groups in catalysis will direct the synthesis of reaction-oriented catalysts. Moreover, recent advances of catalysis rely on in situ characterization techniques, such as in situ infrared (IR) spectroscopy, in situ Raman spectroscopy, in situ X-ray diffraction (XRD), synchrotron X-ray absorption spectroscopy (XAS), and in situ environmental transmission electron microscopy (ETEM). These high-end instruments can provide direct evidence to visualize the metastable intermediates on carbon and to identify the active sites and reaction pathways [144-146]. The obtained results would be conductive in unveiling the mysterious carbocatalysis and guide the rational design of carbocatalysts. Last but not least, due to the fascinating features of graphene-based materials, future studies are encouraged to explore new reactions with metal-free catalysts.

Author Contributions: Conceptualization, S.N. and X.D.; writing-original draft preparation, S.N., W.-J.O. and X.D.; writing-review and editing. All authors have read and agreed to the published version of the manuscript.

Funding: This research was funded by the Fundación Ramón Areces (XVIII Concurso Nacional para la Adjudicación de Ayudas a la Investigación en Ciencias de la Vida y de la Materia, 2016), Ministerio de Ciencia, Innovación y Universidades RTI 2018-099482-A-I00 project and Generalitat Valenciana grupos de investigación consolidables 2019 (ref: AICO/2019/214) project. X.D. acknowledges the support from Pawsey Supercomputing Centre under project No. pawsey0344.

Conflicts of Interest: The authors declare no conflict of interest.

\section{References}

1. Lim, B.; Jiang, M.J.; Camargo, P.H.C.; Cho, E.C.; Tao, J.; Lu, X.M.; Zhu, Y.M.; Xia, Y.N. Pd-Pt bimetallic nanodendrites with high activity for oxygen reduction. Science 2009, 324, 1302-1305. [CrossRef]

2. Wang, Y.G.; Cantu, D.C.; Lee, M.S.; Li, J.; Glezakou, V.A.; Rousseau, R. CO Oxidation on $\mathrm{Au} / \mathrm{TiO}_{2}$ : Condition-dependent active sites and mechanistic pathways. J. Am. Chem. Soc. 2016, 138, 10467-10476. [CrossRef] [PubMed]

3. Hsu, C.S.; Robinson, P.R. Gasoline production. In Petroleum Science and Technology; Hsu, C.S., Robinson, P.R., Eds.; Springer International Publishing: Cham, Switzerland, 2019.

4. Hill, C.K.; Hartwig, J.F. Site-selective oxidation, amination and epimerization reactions of complex polyols enabled by transfer hydrogenation. Nat. Chem. 2017, 9, 1213-1221. [CrossRef] [PubMed]

5. Li, W.; Cui, X.J.; Junge, K.; Surkus, A.E.; Kreyenschulte, C.; Bartling, S.; Beller, M. General and Chemoselective Copper Oxide Catalysts for Hydrogenation Reactions. ACS Catal. 2019, 9, 4302-4307. [CrossRef] 
6. Lee, S.; Halder, A.; Ferguson, G.A.; Seifert, S.; Winans, R.E.; Teschner, D.; Schlogl, R.; Papaefthimiou, V.; Greeley, J.; Curtiss, L.A.; et al. Subnanometer cobalt oxide clusters as selective low temperature oxidative dehydrogenation catalysts. Nat. Commun. 2019, 10, 954. [CrossRef] [PubMed]

7. Jiao, Y.; Zheng, Y.; Jaroniec, M.T.; Qiao, S.Z. Design of electrocatalysts for oxygen- and hydrogen-involving energy conversion reactions. Chem. Soc. Rev. 2015, 44, 2060-2086. [CrossRef] [PubMed]

8. Su, D.S.; Zhang, J.; Frank, B.; Thomas, A.; Wang, X.C.; Paraknowitsch, J.; Schlogl, R. Metal-free heterogeneous catalysis for sustainable chemistry. ChemSusChem 2010, 3, 169-180. [CrossRef]

9. Navalon, S.; Dhakshinamoorthy, A.; Alvaro, M.; Garcia, H. Carbocatalysis by graphene-based materials. Chem. Rev. 2014, 114, 6179-6212. [CrossRef]

10. Park, S.; Ruoff, R.S. Chemical methods for the production of graphenes. Nat. Nanotechnol. 2009, 4, $217-224$. [CrossRef]

11. Novoselov, K.S.; Fal'ko, V.I.; Colombo, L.; Gellert, P.R.; Schwab, M.G.; Kim, K. A roadmap for graphene. Nature 2012, 490, 192-200. [CrossRef]

12. Dreyer, D.R.; Bielawski, C.W. Carbocatalysis: Heterogeneous carbons finding utility in synthetic chemistry. Chem. Sci. 2011, 2, 1233-1240. [CrossRef]

13. Primo, A.; Parvulescu, V.I.; Garcia, H. Graphenes as metal-free catalysts with engineered active sites. J. Phys. Chem. Lett. 2016, 8, 264-278. [CrossRef] [PubMed]

14. Hummers, W.S.; Offeman, R.E. Preparation of graphitic oxide. J. Am. Chem. Soc. 1958, 80, 1339. [CrossRef]

15. Chen, J.; Yao, B.; Li, C.; Shi, G. An improved Hummers method for eco-friendly synthesis of graphene oxide. Carbon 2013, 64, 225-229. [CrossRef]

16. Zhu, Y.; Murali, S.; Cai, W.; Li, X.; Suk, J.W.; Potts, J.R.; Ruoff, R.S. Graphene and graphene oxide: Synthesis, properties, and applications. Adv. Mater. 2010, 22, 3906-3924. [CrossRef]

17. Fu, Q.; Bao, X.H. Surface chemistry and catalysis confined under two-dimensional materials. Chem. Soc. Rev. 2017, 46, 1842-1874. [CrossRef]

18. Geim, A.K.; Novoselov, K.S. The rise of graphene. Natur. Mater. 2007, 6, 183-191. [CrossRef]

19. Chen, X.; Oh, W.D.; Lim, T.T. Graphene- and CNTs-based carbocatalysts in persulfates activation: Material design and catalytic mechanisms. Chem. Eng. J. 2018, 354, 941-976. [CrossRef]

20. Frank, B.; Blume, R.; Rinaldi, A.; Trunschke, A.; Schlögl, R. Oxygen insertion catalysis by sp ${ }^{2}$ carbon. Angew. Chem. Int. Ed. 2011, 50, 10226-10230. [CrossRef]

21. Kong, X.K.; Chen, C.L.; Chen, Q.W. Doped graphene for metal-free catalysis. Chem. Soc. Rev. 2014, 43, 2841-2857. [CrossRef]

22. Navalon, S.; Dhakshinamoorthy, A.; Alvaro, M.; Antonietti, M.; García, H. Active sites on graphene-based materials as metal-free catalysts. Chem. Soc. Rev. 2017, 46, 4501-4529. [CrossRef] [PubMed]

23. Su, D.S.; Wen, G.D.; Wu, S.C.; Peng, F.; Schlogl, R. Carbocatalysis in Liquid-Phase Reactions. Angew. Chem. Int. Edit 2017, 56, 936-964. [CrossRef] [PubMed]

24. Duan, J.; Chen, S.; Jaroniec, M.; Qiao, S.Z. Heteroatom-doped graphene-based materials for energy-relevant electrocatalytic processes. ACS Catal. 2015, 5, 5207-5234. [CrossRef]

25. Jana, D.; Sun, C.-L.; Chen, L.-C.; Chen, K.-H. Effect of chemical doping of boron and nitrogen on the electronic, optical, and electrochemical properties of carbon nanotubes. Prog. Mater. Sci. 2013, 58, 565-635. [CrossRef]

26. Wang, H.; Maiyalagan, T.; Wang, X. Review on recent progress in nitrogen-doped graphene: Synthesis, characterization, and its potential applications. ACS Catal. 2012, 2, 781-794. [CrossRef]

27. Rao, C.N.R.; Gopalakrishnan, K.; Govindaraj, A. Synthesis, properties and applications of graphene doped with boron, nitrogen and other elements. Nano Today 2014, 9, 324-343. [CrossRef]

28. Kim, K.S.; Zhao, Y.; Jang, H.; Lee, S.Y.; Kim, J.M.; Kim, K.S.; Ahn, J.H.; Kim, P.; Choi, J.Y.; Hong, B.H. Large-scale pattern growth of graphene films for stretchable transparent electrodes. Nature 2009, 457, 706-710. [CrossRef]

29. Zhang, B.B.; Song, J.L.; Yang, G.Y.; Han, B.X. Large-scale production of high-quality graphene using glucose and ferric chloride. Chem. Sci. 2014, 5, 4656-4660. [CrossRef]

30. Kashani, H.; Ito, Y.; Han, J.H.; Liu, P.; Chen, M.W. Extraordinary tensile strength and ductility of scalable nanoporous graphene. Sci. Adv. 2019, 5, eaat6951. [CrossRef]

31. Liu, H.T.; Liu, Y.Q.; Zhu, D.B. Chemical doping of graphene. J. Mater. Chem. 2011, 21, 3335-3345. [CrossRef]

32. Castro Neto, A.H.; Guinea, F.; Peres, N.M.R.; Novoselov, K.S.; Geim, A.K. The electronic properties of graphene. Rev. Mod. Phys. 2009, 81, 109-162. [CrossRef] 
33. Yang, X.F.; Wang, A.Q.; Qiao, B.T.; Li, J.; Liu, J.Y.; Zhang, T. Single-atom catalysts: A new frontier in heterogeneous catalysis. Accounts Chem. Res. 2013, 46, 1740-1748. [CrossRef] [PubMed]

34. Zhang, H.B.; Liu, G.G.; Shi, L.; Ye, J.H. Single-atom catalysts: Emerging multifunctional materials in heterogeneous catalysis. Adv. Energy Mater. 2018, 8, 1701343. [CrossRef]

35. Wang, A.; Li, J.; Zhang, T. Heterogeneous single-atom catalysis. Nat. Rev. Chem. 2018, 2, 65-81. [CrossRef]

36. Su, C.; Acik, M.; Takai, K.; Lu, J.; Hao, S.J.; Zheng, Y.; Wu, P.; Bao, Q.; Enoki, T.; Chabal, Y.J.; et al. Probing the catalytic activity of porous graphene oxide and the origin of this behaviour. Nat. Commun. 2012, 3, 1298. [CrossRef]

37. Jiang, D.E.; Sumpter, B.G.; Dai, S. Unique chemical reactivity of a graphene nanoribbon's zigzag edge. J. Chem. Phys. 2007, 126, 134701. [CrossRef] [PubMed]

38. Tang, C.; Zhang, Q. Nanocarbon for oxygen reduction electrocatalysis: Dopants, edges, and defects. Adv. Mater. 2017, 29, 1604103. [CrossRef]

39. Tang, C.; Wang, H.F.; Chen, X.; Li, B.Q.; Hou, T.Z.; Zhang, B.S.; Zhang, Q.; Titirici, M.M.; Wei, F. Topological defects in metal-free nanocarbon for oxygen electrocatalysis. Adv. Mater. 2016, 28, 6845-6851. [CrossRef]

40. Tian, W.; Zhang, H.; Duan, X.; Sun, H.; Shao, G.; Wang, S. Porous carbons: Structure-oriented design and versatile applications. Adv. Funct. Mater. 2020, 30, 1909265. [CrossRef]

41. Yang, Q.; Xiao, Z.; Kong, D.; Zhang, T.; Duan, X.; Zhou, S.; Niu, Y.; Shen, Y.; Sun, H.; Wang, S.; et al. New insight to the role of edges and heteroatoms in nanocarbons for oxygen reduction reaction. Nano Energ. 2019, 66, 104096. [CrossRef]

42. Tian, Y.; Ye, Y.F.; Wang, X.J.; Peng, S.; Wei, Z.; Zhang, X.; Liu, W.M. Three-dimensional N-doped, plasma-etched graphene: Highly active metal-free catalyst for hydrogen evolution reaction. Appl. Catal. A-Gen. 2017, 529, 127-133. [CrossRef]

43. Jia, Y.; Zhang, L.Z.; Du, A.J.; Gao, G.P.; Chen, J.; Yan, X.C.; Brown, C.L.; Yao, X.D. Defect graphene as a trifunctional catalyst for electrochemical reactions. Adv. Mater. 2016, 28, 9532-9538. [CrossRef] [PubMed]

44. Carlsson, J.M.; Scheffler, M. Structural, electronic, and chemical properties of nanoporous carbon. Phys. Rev. Lett. 2006, 96, 046806. [CrossRef] [PubMed]

45. Lei, Y.-J.; Tian, Y.; Sobhani, Z.; Naidu, R.; Fang, C. Synergistic degradation of PFAS in water and soil by dual-frequency ultrasonic activated persulfate. Chem. Eng. J. 2020, 388, 124215. [CrossRef]

46. Han, W.; Li, D.; Zhang, M.; Ximin, H.; Duan, X.; Liu, S.; Wang, S. Photocatalytic activation of peroxymonosulfate by surface-tailored carbon quantum dots. J. Hazard. Mater. 2020, 395, 122695. [CrossRef]

47. Duan, X.; Indrawirawan, S.; Kang, J.; Tian, W.; Zhang, H.; Sun, H.; Wang, S. Temperature-dependent evolution of hydroxyl radicals from peroxymonosulfate activation over nitrogen-modified carbon nanotubes. Sustain. Mater. Technol. 2018, 18, e00082. [CrossRef]

48. Duan, X.; Indrawirawan, S.; Kang, J.; Tian, W.; Zhang, H.; Duan, X.; Zhou, X.; Sun, H.; Wang, S. Synergy of carbocatalytic and heat activation of persulfate for evolution of reactive radicals toward metal-free oxidation. Catal. Today 2019. [CrossRef]

49. Nie, C.Y.; Ao, Z.M.; Duan, X.G.; Wang, C.Y.; Wang, S.B.; An, T.C. Degradation of aniline by electrochemical activation of peroxydisulfate at MWCNT cathode: The proofed concept of nonradical oxidation process. Chemosphere 2018, 206, 432-438. [CrossRef]

50. Anipsitakis, G.P.; Dionysiou, D.D. Radical generation by the interaction of transition metals with common oxidants. Environ. Sci. Technol. 2004, 38, 3705-3712. [CrossRef]

51. Duan, X.G.; Sun, H.Q.; Wang, S.B. Metal-free carbocatalysis in advanced oxidation reactions. Accounts Chem. Res. 2018, 51, 678-687. [CrossRef]

52. Espinosa, J.C.; Navalon, S.; Alvaro, M.; Garcia, H. Reduced graphene oxide as a metal-free catalyst for the light-assisted fenton-like reaction. Chemcatchem 2016, 8, 2642-2648. [CrossRef]

53. Bernat-Quesada, F.; Espinosa, J.C.; Barbera, V.; Alvaro, M.; Galimberti, M.; Navalon, S.; Garcia, H. Catalytic ozonation using edge-hydroxylated graphite-based materials. ACS Sustain. Chem. Eng. 2019, 7, 17443-17452. [CrossRef]

54. Sun, H.Q.; Liu, S.Z.; Zhou, G.L.; Ang, H.M.; Tade, M.O.; Wang, S.B. Reduced graphene oxide for catalytic oxidation of aqueous organic pollutants. ACS Appl. Mater. Interfaces 2012, 4, 5466-5471. [CrossRef] [PubMed]

55. Duan, X.G.; Sun, H.Q.; Ao, Z.M.; Zhou, L.; Wang, G.X.; Wang, S.B. Unveiling the active sites of graphene-catalyzed peroxymonosulfate activation. Carbon 2016, 107, 371-378. [CrossRef] 
56. Duan, X.G.; Ao, Z.M.; Zhou, L.; Sun, H.Q.; Wang, G.X.; Wang, S.B. Occurrence of radical and nonradical pathways from carbocatalysts for aqueous and nonaqueous catalytic oxidation. Appl. Catal. B-Environ. 2016, 188, 98-105. [CrossRef]

57. Han, C.; Duan, X.G.; Zhang, M.J.; Fu, W.Z.; Duan, X.Z.; Ma, W.J.; Liu, S.M.; Wang, S.B.; Zhou, X.G. Role of electronic properties in partition of radical and nonradical processes of carbocatalysis toward peroxymonosulfate activation. Carbon 2019, 153, 73-80. [CrossRef]

58. Cheng, X.; Guo, H.; Zhang, Y.; Wu, X.; Liu, Y. Non-photochemical production of singlet oxygen via activation of persulfate by carbon nanotubes. Water Res. 2017, 113, 80-88. [CrossRef]

59. Li, D.; Duan, X.; Sun, H.; Kang, J.; Zhang, H.; Tade, M.O.; Wang, S. Facile synthesis of nitrogen-doped graphene via low-temperature pyrolysis: The effects of precursors and annealing ambience on metal-free catalytic oxidation. Carbon 2017, 115, 649-658. [CrossRef]

60. Kang, J.; Duan, X.G.; Zhou, L.; Sun, H.Q.; Tade, M.O.; Wang, S.B. Carbocatalytic activation of persulfate for removal of antibiotics in water solutions. Chem. Eng. J. 2016, 288, 399-405. [CrossRef]

61. Liang, P.; Zhang, C.; Duan, X.G.; Sun, H.Q.; Liu, S.M.; Tade, M.O.; Wang, S.B. N-Doped Graphene from Metal-Organic Frameworks for Catalytic Oxidation of p-HydroxylbenzoicL Acid: N-Functionality and Mechanism. ACS Sustain. Chem. Eng. 2017, 5, 2693-2701. [CrossRef]

62. Liang, P.; Zhang, C.; Duan, X.; Sun, H.; Liu, S.; Tade, M.O.; Wang, S. An insight into metal organic framework derived N-doped graphene for the oxidative degradation of persistent contaminants: Formation mechanism and generation of singlet oxygen from peroxymonosulfate. Environ. Sci. Nano 2017, 4, 315-324. [CrossRef]

63. Kang, J.; Zhou, L.; Duan, X.; Sun, H.; Wang, S. Catalytic degradation of antibiotics by metal-free catalysis over nitrogen-doped graphene. Catal. Today 2018. [CrossRef]

64. Duan, X.G.; Ao, Z.M.; Sun, H.Q.; Indrawirawan, S.; Wang, Y.X.; Kang, J.; Liang, F.L.; Zhu, Z.H.; Wang, S.B. Nitrogen-doped graphene for generation and evolution of reactive radicals by metal-free catalysis. ACS Appl. Mater. Interfaces 2015, 7, 4169-4178. [CrossRef] [PubMed]

65. Duan, X.G.; Sun, H.Q.; Wang, Y.X.; Kang, J.; Wang, S.B. N-doping-induced nonradical reaction on single-walled carbon nanotubes for catalytic phenol oxidation. ACS Catal. 2015, 5, 553-559. [CrossRef]

66. Wu, D.; Song, W.Y.; Chen, L.L.; Duan, X.G.; Xia, Q.; Fan, X.B.; Li, Y.; Zhang, F.B.; Peng, W.C.; Wang, S.B. High-performance porous graphene from synergetic nitrogen doping and physical activation for advanced nonradical oxidation. J. Hazard. Mater. 2020, 381, 121010. [CrossRef]

67. Yang, Z.; Duan, X.; Wang, J.; Li, Y.; Fan, X.; Zhang, F.; Zhang, G.; Peng, W. Facile synthesis of high-performance nitrogen-doped hierarchically porous carbon for catalytic oxidation. ACS Sustain. Chem. Eng. 2020, 8, 4236-4243. [CrossRef]

68. Zhang, W.; Li, Y.; Fan, X.B.; Zhang, F.B.; Zhang, G.L.; Zhu, Y.A.; Peng, W.C.; Wang, S.B.; Duan, X.G. Synergy of nitrogen doping and structural defects on hierarchically porous carbons toward catalytic oxidation via a non-radical pathway. Carbon 2019, 155, 268-278. [CrossRef]

69. Duan, X.G.; O'Donnell, K.; Sun, H.Q.; Wang, Y.X.; Wang, S.B. Sulfur and nitrogen co-doped graphene for metal-free catalytic oxidation reactions. Small 2015, 11, 3036-3044. [CrossRef]

70. Liu, H.; Sun, P.; Feng, M.B.; Liu, H.X.; Yang, S.G.; Wang, L.S.; Wang, Z.Y. Nitrogen and sulfur co-doped $\mathrm{CNT}-\mathrm{COOH}$ as an efficient metal-free catalyst for the degradation of UV filter BP-4 based on sulfate radicals. Appl. Catal. B Environ. 2016, 187, 1-10. [CrossRef]

71. Chen, X.; Duan, X.G.; Oh, W.D.; Zhang, P.H.; Guan, C.T.; Zhu, Y.A.; Lim, T.T. Insights into nitrogen and boron-co-doped graphene toward high-performance peroxymonosulfate activation: Maneuverable N-B bonding configurations and oxidation pathways. Appl. Catal. B Environ. 2019, 253, 419-432. [CrossRef]

72. Sun, H.Q.; Wang, Y.X.; Liu, S.Z.; Ge, L.; Wang, L.; Zhu, Z.H.; Wang, S.B. Facile synthesis of nitrogen doped reduced graphene oxide as a superior metal-free catalyst for oxidation. Chem. Commun. 2013, 49, 9914-9916. [CrossRef] [PubMed]

73. Duan, X.G.; Tian, W.J.; Zhang, H.Y.; Sun, H.Q.; Ao, Z.M.; Shao, Z.P.; Wang, S.B. sp(2)/sp(3) framework from diamond nanocrystals: A key bridge of carbonaceous structure to carbocatalysis. ACS Catal. 2019, 9, 7494-7519. [CrossRef]

74. Navalón, S.; Dhakshinamoorthy, A.; Álvaro, M.; García, H. Diamond nanoparticles in heterogeneous catalysis. Chem. Mater. 2020, 32, 4116-4143. [CrossRef] 
75. Duan, X.G.; Ao, Z.M.; Zhang, H.Y.; Saunders, M.; Sun, H.Q.; Shao, Z.P.; Wang, S.B. Nanodiamonds in sp2/sp3 configuration for radical to nonradical oxidation: Core-shell layer dependence. Appl. Catal. B Environ. 2018, 222, 176-181. [CrossRef]

76. Duan, X.G.; Ao, Z.M.; Li, D.G.; Sun, H.Q.; Zhou, L.; Suvorova, A.; Saunders, M.; Wang, G.X.; Wang, S.B. Surface-tailored nanodiamonds as excellent metal-free catalysts for organic oxidation. Carbon 2016, 103, 404-411. [CrossRef]

77. Duan, X.G.; Su, C.; Zhou, L.; Sun, H.Q.; Suvorova, A.; Odedairo, T.; Zhu, Z.H.; Shao, Z.P.; Wang, S.B. Surface controlled generation of reactive radicals from persulfate by carbocatalysis on nanodiamonds. Appl. Catal. B Environ. 2016, 194, 7-15. [CrossRef]

78. Shao, P.; Tian, J.; Yang, F.; Duan, X.; Gao, S.; Shi, W.; Luo, X.; Cui, F.; Luo, S.; Wang, S. Identification and regulation of active sites on nanodiamonds: Establishing a highly efficient catalytic system for oxidation of organic contaminants. Adv. Funct. Mater. 2018, 28, 1705295. [CrossRef]

79. Li, H.R.; Tian, J.Y.; Zhu, Z.G.; Cui, F.Y.; Zhu, Y.A.; Duan, X.G.; Wang, S.B. Magnetic nitrogen-doped nanocarbons for enhanced metal-free catalytic oxidation: Integrated experimental and theoretical investigations for mechanism and application. Chem. Eng. J. 2018, 354, 507-516. [CrossRef]

80. Kang, J.; Zhang, H.Y.; Duan, X.G.; Sun, H.Q.; Tan, X.Y.; Liu, S.M.; Wang, S.B. Magnetic Ni-Co alloy encapsulated $\mathrm{N}$-doped carbon nanotubes for catalytic membrane degradation of emerging contaminants. Chem. Eng. J. 2019, 362, 251-261. [CrossRef]

81. Zhou, H.; Wu, S.K.; Zhou, Y.Y.; Yang, Y.; Zhang, J.C.; Luo, L.; Duan, X.G.; Wang, S.B.; Wang, L.; Tsang, D.C.W. Insights into the oxidation of organic contaminants by iron nanoparticles encapsulated within boron and nitrogen co-doped carbon nanoshell: Catalyzed Fenton-like reaction at natural pH. Environ. Int. 2019, 128, 77-88. [CrossRef]

82. Wang, Y.X.; Sun, H.Q.; Duan, X.G.; Ang, H.M.; Tade, M.O.; Wang, S.B. A new magnetic nano zero-valent iron encapsulated in carbon spheres for oxidative degradation of phenol. Appl. Catal. B Environ. 2015, 172, $73-81$. [CrossRef]

83. Kang, J.; Zhou, L.; Duan, X.G.; Sun, H.Q.; Ao, Z.M.; Wang, S.B. Degradation of cosmetic microplastics via functionalized carbon nanosprings. Matter 2019, 1, 745-758. [CrossRef]

84. Kang, J.; Duan, X.; Wang, C.; Sun, H.; Tan, X.; Tade, M.O.; Wang, S. Nitrogen-doped bamboo-like carbon nanotubes with $\mathrm{Ni}$ encapsulation for persulfate activation to remove emerging contaminants with excellent catalytic stability. Chem. Eng. J. 2018, 332, 398-408. [CrossRef]

85. Kang, J.; Zhang, H.; Duan, X.; Sun, H.; Tan, X.; Wang, S. Nickel in hierarchically structured nitrogen-doped graphene for robust and promoted degradation of antibiotics. J. Cleaner Prod. 2019, 218, 202-211. [CrossRef]

86. Duan, X.G.; Kang, J.; Tian, W.J.; Zhang, H.Y.; Ho, S.H.; Zhu, Y.A.; Ao, Z.M.; Sun, H.Q.; Wang, S.B. Interfacial-engineered cobalt@carbon hybrids for synergistically boosted evolution of sulfate radicals toward green oxidation. Appl. Catal. B Environ. 2019, 256. [CrossRef]

87. Zhu, S.; Jin, C.; Duan, X.; Wang, S.; Ho, S.-H. Nonradical oxidation in persulfate activation by graphene-like nanosheets (GNS): Differentiating the contributions of singlet oxygen $\left({ }^{1} \mathrm{O}_{2}\right)$ and sorption-dependent electron transfer. Chem. Eng. J. 2020, 393, 124725. [CrossRef]

88. Duan, X.G.; Sun, H.Q.; Kang, J.; Wang, Y.X.; Indrawirawan, S.; Wang, S.B. Insights into heterogeneous catalysis of persulfate activation on dimensional-structured nanocarbons. ACS Catal. 2015, 5, 4629-4636. [CrossRef]

89. Duan, X.G.; Sun, H.Q.; Shao, Z.P.; Wang, S.B. Nonradical reactions in environmental remediation processes: Uncertainty and challenges. Appl. Catal. B Environ. 2018, 224, 973-982. [CrossRef]

90. Cheng, X.; Guo, H.; Zhang, Y.; Korshin, G.V.; Yang, B. Insights into the mechanism of nonradical reactions of persulfate activated by carbon nanotubes: Activation performance and structure-function relationship. Water Res. 2019, 157, 406-414. [CrossRef]

91. Ren, W.; Xiong, L.L.; Nie, G.; Zhang, H.; Duan, X.G.; Wang, S.B. Insights into the electron-transfer regime of peroxydisulfate activation on carbon nanotubes: The role of oxygen functional groups. Environ. Sci. Technol. 2020, 54, 1267-1275. [CrossRef]

92. Ren, W.; Xiong, L.; Yuan, X.; Yu, Z.; Zhang, H.; Duan, X.; Wang, S. Activation of peroxydisulfate on carbon nanotubes: Electron-transfer mechanism. Environ. Sci. Technol. 2019, 53, 14595-14603. [CrossRef] [PubMed] 
93. Su, H.; Wei, Y.; Qu, X.; Yu, C.; Li, Q.; Alvarez, P.J.J.; Long, M. Mechanistic inference on the reaction kinetics of phenols and anilines in carbon nanotubes-activated peroxydisulfate systems: pp-LFERs and QSARs analyses. Chem. Eng. J. 2020, 385, 123923. [CrossRef]

94. Sun, H.Q.; Kwan, C.; Suvorova, A.; Ang, H.M.; Tade, M.O.; Wang, S.B. Catalytic oxidation of organic pollutants on pristine and surface nitrogen-modified carbon nanotubes with sulfate radicals. Appl. Catal. B Environ. 2014, 154, 134-141. [CrossRef]

95. Ren, W.; Nie, G.; Zhou, P.; Zhang, H.; Duan, X.; Wang, S. The Intrinsic nature of persulfate activation and N-doping in carbocatalysis. Environ. Sci. Technol. 2020, 54, 6438-6447. [CrossRef]

96. Duan, X.G.; Ao, Z.M.; Sun, H.Q.; Zhou, L.; Wang, G.X.; Wang, S.B. Insights into N-doping in single-walled carbon nanotubes for enhanced activation of superoxides: A mechanistic study. Chem. Commun. 2015, 51, 15249-15252. [CrossRef]

97. Tian, W.J.; Zhang, H.Y.; Duan, X.G.; Sun, H.Q.; Tade, M.O.; Ang, H.M.; Wang, S.B. Nitrogenand sulfur-codoped hierarchically porous carbon for adsorptive and oxidative removal of pharmaceutical contaminants. ACS Appl. Mater. Interfaces 2016, 8, 7184-7193. [CrossRef]

98. Wang, J.; Duan, X.; Dong, Q.; Meng, F.; Tan, X.; Liu, S.; Wang, S. Facile synthesis of N-doped 3D graphene aerogel and its excellent performance in catalytic degradation of antibiotic contaminants in water. Carbon 2019, 144, 781-790. [CrossRef]

99. Indrawirawan, S.; Sun, H.Q.; Duan, X.G.; Wang, S.B. Nanocarbons in different structural dimensions (0-3D) for phenol adsorption and metal-free catalytic oxidation. Appl. Catal. B Environ. 2015, 179, 352-362. [CrossRef]

100. Ertl, G.; Freund, H.J. Catalysis and surface science. Phys. Today 1999, 52, 32-38. [CrossRef]

101. Schlögl, R. Heterogeneous catalysis—still magic or already science? Angew. Chem. Int. Ed..

102. Somorjai, G.A. The surface science of heterogeneous catalysis. Surf. Sci..

103. Chua, C.K.; Pumera, M. Carbocatalysis: The State of metal-free catalysis. Chem. Eur. J. 2015, 21, 12550-12562. [CrossRef]

104. Liu, L.; Zhu, Y.P.; Su, M.; Yuan, Z.Y. Metal-free carbonaceous materials as promising heterogeneous catalysts. ChemCatChem 2015, 7, 2765-2787. [CrossRef]

105. Navalón, S.; Herance, J.R.; Alvaro, M.; García, H. General aspects in the use of graphenes in catalysis. Mater. Horiz. 2018, 5, 363-378. [CrossRef]

106. Navalón, S.; Herance, J.R.; lvaro, M.; García, H. Covalently modified graphenes in catalysis, electrocatalysis and photoresponsive materials. Chem. Eur. J. 2017, 23, 15244-15275. [CrossRef] [PubMed]

107. Su, D.S.; Perathoner, S.; Centi, G. Nanocarbons for the development of advanced catalysts. Chem. Rev. 2013, 113, 5782-5816. [CrossRef]

108. Tang, P.; Hu, G.; Li, M.; Ma, D. Graphene-based metal-free catalysts for catalytic reactions in the liquid phase. ACS Catal. 2016, 6, 6948-6958. [CrossRef]

109. Thomas, A.; Fischer, A.; Goettmann, F.; Antonietti, M.; Mueller, J.-O.; Schloegl, R.; Carlsson, J.M. Graphitic carbon nitride materials: Variation of structure and morphology and their use as metal-free catalysts. J. Mater. Chem. 2008, 18, 4893-4908. [CrossRef]

110. Wang, X.; Sun, G.; Routh, P.; Kim, D.-H.; Huang, W.; Chen, P. Heteroatom-doped graphene materials: Syntheses, properties and applications. Chem. Soc. Rev. 2014, 43, 7067-7098. [CrossRef]

111. Zhai, Y.; Zhu, Z.; Dong, S. Carbon-based nanostructures for advanced catalysis. ChemCatChem 2015, 7, 2806-2815. [CrossRef]

112. Espinosa, J.C.; Navalon, S.; Alvaro, M.; Dhakshinamoorthy, A.; Garcia, H. Reduction of C=C double bonds by hydrazine using active carbons as metal-free catalysts. ACS Sustain. Chem. Eng. 2018, 6, 5607-5614. [CrossRef]

113. Blandez, J.F.; Navalon, S.; Alvaro, M.; Garcia, H. Graphenes as metal-free catalysts for the oxidative depolymerization of lignin models. ChemCatChem 2015, 7, 3020-3026. [CrossRef]

114. Primo, A.; Navalon, S.; Asiri, A.M.; Garcia, H. Chitosan-templated synthesis of few-layers boron nitride and its unforeseen activity as a fenton catalyst. Chem. Eur. J. 2015, 21, 324-330. [CrossRef] [PubMed]

115. Yang, Q.; Chen, Y.; Duan, X.; Zhou, S.; Niu, Y.; Sun, H.; Zhi, L.; Wang, S. Unzipping carbon nanotubes to nanoribbons for revealing the mechanism of nonradical oxidation by carbocatalysis. Appl. Catal. B Environ. 2020, 276, 119146. [CrossRef] 
116. Wang, Y.; Xi, J.; Duan, X.; Lv, W.; Cao, H.; Chen, C.; Guo, Z.; Xie, Y.; Wang, S. The duet of surface and radical-based carbocatalysis for oxidative destructions of aqueous contaminants over built-in nanotubes of graphite. J. Hazard. Mater. 2020, 384, 121486. [CrossRef] [PubMed]

117. Wang, Y.; Chen, L.; Chen, C.; Xi, J.; Cao, H.; Duan, X.; Xie, Y.; Song, W.; Wang, S. Occurrence of both hydroxyl radical and surface oxidation pathways in N-doped layered nanocarbons for aqueous catalytic ozonation. Appl. Catal. B Environ. 2019, 254, 283-291. [CrossRef]

118. Cadus, L.E.; Arrua, L.A.; Gorriz, O.F.; Rivarola, J.B. Action of activated coke as a catalyst: Oxydehydrogenation of ethylbenzene to styrene. Ind. Eng. Chem. Res. 1988, 27, 2241-2246. [CrossRef]

119. Emig, G.; Hofmann, H. Action of zirconium phosphate as a catalyst for the oxydehydrogenation of ethylbenzene to styrene. J. Catal. 1983, 84, 15-26. [CrossRef]

120. Schraut, A.; Emig, G.; Sockel, H.G. Composition and structure of active coke in the oxydehydrogenation of ethylbenzene. Appl. Catal. 1987, 29, 311-326. [CrossRef]

121. Vrieland, G.E. Oxydehydrogenation of ethylbenzene to styrene over metal pyrophosphates: 1 . Catalyst composition and reaction variables. J. Catal. 1988, 111, 1-13. [CrossRef]

122. Liu, X.; Dai, L. Carbon-based metal-free catalysts. Nat. Rev. Mater. 2016, 16064. [CrossRef]

123. Dreyer, D.R.; Jia, H.P.; Bielawski, C.W. Graphene Oxide: A convenient carbocatalyst for facilitating oxidation and hydration reactions. Angew. Chem. Int. Ed. 2010, 49, 6813-6816. [CrossRef]

124. Dreyer, D.R.; Park, S.; Bielawski, C.W.; Ruoff, R.S. The chemistry of graphene oxide. Chem. Soc. Rev. 2010, 39, 228-240. [CrossRef] [PubMed]

125. Chua, C.K.; Pumera, M. Chemical reduction of graphene oxide: A synthetic chemistry viewpoint. Chem. Soc. Rev. 2014, 43, 291-312. [CrossRef] [PubMed]

126. Corma, A.; Garcia, H. Supported gold nanoparticles as catalysts for organic reactions. Chem. Soc. Rev. 2008, 37, 2096-2126. [CrossRef] [PubMed]

127. Haruta, M.; Yamada, N.; Kobayashi, T.; Iijima, S. Gold catalysts prepared by coprecipitation for low-temperature oxidation of hydrogen and of carbon monoxide. J. Catal. 1989, 115, 301-309. [CrossRef]

128. Hashmi, A.S.K.; Hutchings, G.J. Gold catalysis. Angew. Chem. Int. Ed. 2006, 45, 7896-7936. [CrossRef]

129. Punniyamurthy, T.; Velusamy, S.; Iqbal, J. Recent advances in transition metal catalyzed oxidation of organic substrates with molecular oxygen. Chem. Rev. 2005, 105, 2329-2363. [CrossRef]

130. Boukhvalov, D.W.; Dreyer, D.R.; Bielawski, C.W.; Son, Y.-W. A computational investigation of the catalytic properties of graphene oxide: Exploring mechanisms by using DFT methods. ChemCatChem 2012, 4, 1844-1849. [CrossRef]

131. Espinosa, J.C.; Álvaro, M.; Dhakshinamoorthy, A.; Navalón, S.; García, H. Engineering active sites in reduced graphene oxide: Tuning the catalytic activity for aerobic oxidation. ACS Sustainable Chem. Eng. 2019, 7, 15948-15956. [CrossRef]

132. Lam, J.; Szkop, K.M.; Mosaferi, E.; Stephan, D.W. FLP catalysis: Main group hydrogenations of organic unsaturated substrates. Chem. Soc. Rev. 2019, 48, 3592-3612. [CrossRef]

133. Zhang, L.; Zhou, M.; Wang, A.; Zhang, T. Selective hydrogenation over supported metal catalysts: From nanoparticles to single atoms. Chem. Rev. 2019, 120, 683-733. [CrossRef]

134. Bridier, B.; Lopez, N.; Perez-Ramirez, J. Molecular understanding of alkyne hydrogenation for the design of selective catalysts. Dalton Trans. 2010, 39, 8412-8419. [CrossRef]

135. Teschner, D.; Borsodi, J.; Wootsch, A.; Révay, Z.; Hävecker, M.; Knop-Gericke, A.; Jackson, S.D.; Schlögl, R. The roles of subsurface carbon and hydrogen in palladium catalyzed alkyne hydrogenation. Science 2008, 320, 86-89. [CrossRef] [PubMed]

136. Navalón, S.; Álvaro, M.; Dhakshinamoorthy, A.; García, H. Encapsulation of metal nanoparticles within metal-organic frameworks for the reduction of nitro compounds. Molecules 2019, 24, 3050. [CrossRef] [PubMed]

137. Serna, P.; Corma, A. Transforming nano metal nonselective particulates into chemoselective catalysts for hydrogenation of substituted nitrobenzenes. ACS Catal. 2015, 5, 7114-7121. [CrossRef]

138. Primo, A.; Neatu, F.; Florea, M.; Parvulescu, V.; Garcia, H. Graphenes in the absence of metals as carbocatalysts for selective acetylene hydrogenation and alkene hydrogenation. Nat. Commun. 2014, 5, 5291. [CrossRef] [PubMed]

139. Scott, D.J.; Fuchter, M.J.; Ashley, A.E. Designing effective 'frustrated Lewis pair' hydrogenation catalysts. Chem. Soc. Rev. 2017, 46, 5689-5700. [CrossRef] [PubMed] 
140. Stephan, D.W.; Erker, G. Frustrated lewis pairs: Metal-free hydrogen activation and more. Angew. Chem. Int. Ed. 2010, 49, 46-76. [CrossRef]

141. Ding, Y.; Huang, X.; Yi, X.; Qiao, Y.; Sun, X.; Zheng, A.; Su, D.S. A heterogeneous metal-free catalyst for hydrogenation: Lewis acid-base pairs integrated into a carbon lattice. Angew. Chem. Int. Ed. 2018, 57, 13800-13804. [CrossRef]

142. Trandafir, M.-M.; Florea, M.; Neatu, F.; Primo, A.; Parvulescu, V.I.; Garcia, H. Graphene from alginate pyrolysis as a metal-free catalyst for hydrogenation of nitro compounds. ChemSusChem 2016, 9, 1565-1569. [CrossRef]

143. Jurca, B.; Bucur, C.; Primo, A.; Concepción, P.; Parvulescu, V.I.; García, H. N-doped defective graphene from biomass as catalyst for $\mathrm{CO}_{2}$ hydrogenation to methane. ChemCatChem 2019, 11, 985-990. [CrossRef]

144. Dou, J.; Sun, Z.C.; Opalade, A.A.; Wang, N.; Fu, W.S.; Tao, F. Operando chemistry of catalyst surfaces during catalysis. Chem. Soc. Rev. 2017, 46, 2001-2027. [CrossRef] [PubMed]

145. Li, X.N.; Wang, H.Y.; Yang, H.B.; Cai, W.Z.; Liu, S.; Liu, B. In situ/operando characterization techniques to probe the electrochemical reactions for energy conversion. Small Methods 2018, 2, 1700395. [CrossRef]

146. Li, X.; Wang, S.; Li, L.; Sun, Y.; Xie, Y. Progress and perspective for in situ studies of $\mathrm{CO}_{2}$ reduction. J. Am. Chem. Soc. 2020, 142, 9567-9581. [PubMed]

(C) 2020 by the authors. Licensee MDPI, Basel, Switzerland. This article is an open access article distributed under the terms and conditions of the Creative Commons Attribution (CC BY) license (http://creativecommons.org/licenses/by/4.0/). 